\title{
The Effectiveness of Group Positive-Therapy (PPT) and Well-Being Therapy (WBT) on Attitude towards Drug Abuse in Patients under Methadone Maintenance Therapy
}

\author{
Pirnia, $\mathrm{B}^{1}$
}

\section{ABSTRACT}

Treatment of substance abuse has been associated with many challenges. The aim of this study is to compare the effectiveness of group positive therapy (PPT) and well-being therapy (WBT) on attitude towards drug abuse in patients under methadone maintenance therapy. The present study is a quasi-experimental with pre-test and post test analysis and control group. The population was including all substance abusers in the city of Lavasan who were resident in the clinics center of city Lavasan. Participants included thirty-six men who were eligible for the study were chosen by random selection method and randomly allocated in three groups. Two groups received positive psychotherapy (PPT) and well-being therapy (WBT) for 2 months, 14 sessions of 1hours (Two times a week), while the control group received no therapy at all. Data were collected by Questionnaire of attitude to drug which was given to the test subjects before and after completion of the therapy. The collected data was put to one way variance analysis and Scheffe's test. The study demonstrated that group positive therapy and well-being therapy had positive effects on the attitude towards drug abuse improvement in both groups who received interventions ( $\mathrm{P}<0.00001, \mathrm{~F}=16.03$ ) in comparison to the control group. Actually, both methods were effective in boosting attitude towards drug. Both positive therapy and well-being therapy methods were found effective in decrease attitude towards drug abuse in patients under methadone maintenance therapy but have not a significant difference between the effectiveness positive-therapy and well-being therapy.

Keywords: Positive Therapy, Well-Being Therapy, Attitude Towards Drug, Methadone Maintenance Therapy.

Addiction and its unpleasant consequences are considered as the most important public health problems in the world (Daley, Marlatt, 2005). According to the World Health Organization reports, it has been shown that there are about 200 million drug addicts in the world, which the highest prevalence of addiction with 8.2 percent is in Iran (Rezai, Delaware, Najafi, 2012). And studies showed that drug abuse is one of the tenth main diseases all over the world (Mathers,

\footnotetext{
${ }^{1}$ PhD Student of Clinical Psychology, University of Science and Culture, Tehran, Iran (c) 2015 I B Pirnia; licensee IJIP. This is an Open Access Research distributed under the terms of the Creative Commons Attribution License (http://creativecommons.org/licenses/by/2.0), which permits unrestricted use, distribution, and reproduction in any Medium, provided the original work is properly cited.
} 


\section{The Effectiveness of Group Positive-Therapy (PPT) and Well-Being Therapy (WBT) on Attitude Towards Drug Abuse in Patients Under Methadone Maintenance Therapy}

Bernard, Iburg, Inoue, Ma Fat et al, 2003) and is increasing day by day (Hyman, Malenka, 2001). Addiction and psychotropic drug abuse in the country is in the fourth place after accidents, injuries, depression diseases and cardiovascular diseases (Naghavi, 2006). Addiction like any other chronic disease requires management over time (Daley, Marlatt, 2005; Termorshuizen, Krol, Prins, Geskus, van den Brin et al, 2005). There unreasonable beliefs play an important role in the etiology and treatment of addiction. Carol believes that the treatment is associated with lower resistance in addicts (Carroll, 2004). Previous studies have shown that the efficacy of medication maintenance therapy without psychosocial interventions have had limited successes (Roozen, de Waart, van der Windt, van den Brink, de Jong, 2006). Therefore, the necessity of psychological treatment is more crucial than ever. A type of psychotherapy that can have a significant role in the field of addiction is treatment focused on positive oriented psychology. Less than two decades ago as a new trend in psychology was discussed called the positive-oriented psychology which deals with human happiness and well-being and quickly enter the field of clinical psychology and counseling. Later Martin Seligman and his apprentice Taieb Rashid raised positive oriented psychotherapy and used it to increase the joy in the life of the third millennium which established away from the ideology of the disease-oriented (DSM) (fadayi, 2009). Positive-oriented psychotherapy relates to the clients' trauma relief with increased meaning and increasing happiness in life (Rashid, 2008). It is used in various situations (Linley, Joseph, 2004; Snyder, Lopez, 2007), and have stable positive results (Duckworth, Steen, Seligman, 2005) and the strengths and weaknesses of individuals are considered and understood simultaneously in positiveoriented psychology (Lopez, Snyder, Rasmussen, 2003). The process of positive oriented psychotherapy according to Rashid (Rashid, 2008) includes fourteen steps (session) and in each of these sessions different thematic or one of positive psychology-oriented structures are reviewed and home assignment is considered for the clients. Seligman and colleagues (Seligman, Rashid, Parks, 2006) in a number of studies have examined the validity of a positive-oriented psychotherapy and psychotherapy. They found that positive oriented individual psychotherapy reduced the symptoms of depression and led to more full recovery in depressed clients with conventional therapy plus medication in antidepressants. Positive-oriented psychotherapy also increases happiness in addition to the reduction of depression symptoms. In one study (Seligman, Rashid, Parks, 2006) positively oriented psychotherapy was used for two groups of mild to moderate depressive students, the results showed a greater reduction in symptoms of depression and more increase in their life satisfaction which was persistent a year later. A summary of the positive-oriented group therapy was tried with children in school which led to increase in their well-being (Rashid, Anjum, 2008). Many home exercises used in the positive-oriented psychotherapy which have done over the Internet in the researches by Seligman and colleagues (Seligman et al, 2005) have been validating. Based on these studies, Rashid concluded that the positive-oriented psychotherapy was effective and had the effect of high to moderate.

Well-being therapy is a new type of therapy in the field of positive oriented psychology which has originated in studies of cognitive behavioral therapy and has been used either alone or in 


\section{The Effectiveness of Group Positive-Therapy (PPT) and Well-Being Therapy (WBT) on Attitude Towards Drug Abuse in Patients Under Methadone Maintenance Therapy}

combination with cognitive behavioral therapy (Fava, Rafanelli, Cazzaro, Conti, Grandi, 1998). Well-being therapy is organized in a short-term therapy plan (eight sessions) and is guiding and problem-focused and based on the model of psychological well-being of the Ryff (Ryff, 1989) in which self-concept, regular memorial writing and interactions of the client and the therapist are used to increase the client's psychological well-being (Peterson, Seligman, 2004). Ryff psychological pattern (Ryff, 1989) has six dimensions, including environmental mastery, personal growth, and purpose of life, autonomy, self-acceptance and positive relationships with others. The purpose of the use of therapist is to help the clients to reach high levels of psychological wellbeing from lower levels of functioning in all six areas of interest, (Fava et al, 1998). Therapist helps the clients to contribute to their optimum functional level from the impairment of the function and their past experience well-being in their life. These experiences are valuable no matter how short. After Clients were informed fully of well-being cases in their lives, in the next stage of therapy, they are helped to identify their beliefs and thoughts that disturb the well-being experience and also their feelings and well-being (Fava et al, 1998). This phase of treatment of identifying the automatic thoughts or irrational beliefs is similar to conventional cognitive therapy (Rafanelli, Park, Fava, 1999).The difference is that in the well-being therapy, client's self-concept of his thoughts are more based on well-being than on the problems and tensions. And in general, the main methods to help the clients to overcome shortcomings in the psychological well-being include automatic thoughts, cognitive restructuring, the timing of activities that produce a sense of mastery and control or pleasure, education, assertiveness, courage and problem solving (Ruini, Fava, 2004). Therefore, due to the significant prevalence of drug use in Iran, this study aimed to compare the effectiveness of positive-oriented psychological treatment (PPT) with well-being therapy (WBT) in group on attitudes to drug abuse in the addicts were treated with methadone.

\section{METHOD}

The present research was a quasi-experimental study using pre-test and post-test with control group. The study population comprised all male addicts treated with methadone maintenance during the winter of 2014 who referred to the methadone maintenance treatment centers in Lavasanat city, Iran. And they were diagnosed having impairment dependence on opiates (opium syrup and crystals) using structured clinical interview conducted by a clinical psychologist according to the fourth edition of the Diagnostic and Statistical Manual of Mental Disorders criteria and were in the methadone maintenance treatment center.

From the population, 39 males were selected and randomly assigned to three groups: positiveoriented treatment (13), well-being (13) and control group $(n=13)$, respectively. During the course of treatment in experimental groups, 2 left before the end of the study, treatment. In the control group, 1 person did not participate in the test. The final number of participants in the positively oriented treatment group was 12 patients, 12 patients in group well-being treatment group and 12 patients were in the control groups which were replaced randomly in groups 1 to 3 . Entry criteria were: 1 ) age range between 20-50 years, 2) a minimum level of literacy 3) a history 


\section{The Effectiveness of Group Positive-Therapy (PPT) and Well-Being Therapy (WBT) on Attitude Towards Drug Abuse in Patients Under Methadone Maintenance Therapy}

of abuse between 1-10 years 4) the amount of methadone prescribed (60 to $120 \mathrm{mg}$ daily in a period of consolidation). Exclusion criteria were as follows: 1) dependence on other materials at the same time 2) personality disorders, retardation or severe mental disorders 3) severe physical diseases. Also, the two groups were homogeneous in terms of social class, age and experience and the possible effect of these variables on the dependent variable was removed. In this study, a demographic questionnaire, the Structured Clinical Interview for Disorders IV.DSM- (SCID) and Drug Attitude Inventory (Rezai, Delaware, Najafi, 2012) were used. Demographic questionnaire was used by the researcher to collect personal information such as age, education, socioeconomic status, history of diabetes, history of substance abuse treatment and preparation time. Structured Clinical Interview for Disorders DSM - IV (SCID) is a clinical interview used for the diagnosis of a disorder according to DSM - IV. The coefficient of inter-rater reliability for SCID has been reported 0.60 (First, Spitzer, Gibbon, Williams, 2002). Diagnostic agreement of this instrument in Persian has been good for most specific and overall diagnosis with higher reliability of 0.60. Kappa coefficients for the current and lifetime diagnosis were obtained as 0.52 and 0.55 , respectively (sharifi et al, 2009).

Drug Attitude Inventory is made by Rezaiee, Delaware and Najafi (Rezai, Delaware, Najafi, 2012) and includes 40 questions with 5 options based on the Likert scale (strongly agree, agree, no comment, disagree, strongly disagree) and consists of three components: attitude the effects of drug use, attitudes toward the dangers of drug use and attitudes toward drug use. Validity of the questionnaire was obtained using principal components analysis and direct varimax rotation and oblimin method. The results of varimax rotation showed that these three factors determine the $27 / 44 \%$ of the total variance of the questionnaire. $18.7 \%$ of the variance is related to the first component (attitude toward the drug), $41 / 17 \%$ of the variance to the second component (attitude toward drug use) and $15.8 \%$ of the variance was related to the third component (attitude toward risks Drugs). The results of the direct oblimin rotation also showed that the equity of the first component was 39/9, second component 20/9 and the third component was 99/4 (Rezai, Delaware, Najafi, 2012).

\section{PROCEDURE}

The present study was conducted in one of the Methadone maintenance treatment centers of Lavasanat, Iran by a clinical psychologist. Research ethical standards were established as written informed consent of the sessions and the condition to leave the study at any point, the participants' privacy, and protection of their well-being and comfort for all participants. In this design, intervention (three levels: positive-oriented treatment group, the well-being treatment group and control) was considered as the independent variable and attitude towards drug abuse as the dependent variable. Positive-oriented intervention was proposed by Rashid (Rashid, 2008) and had the four components of pleasure, engagement, meaning and perfect life. Further, well- 


\section{The Effectiveness of Group Positive-Therapy (PPT) and Well-Being Therapy (WBT) on Attitude Towards Drug Abuse in Patients Under Methadone Maintenance Therapy}

being treatment offered by Reef was implemented in group for 14 sessions, twice a week for one hour.

After the sessions, all participants in both groups were evaluated by the scale drug attitude and rate of change in the index was also evaluated. ANOVA and Scheffe post hoc test were used to compare the three independent variables (both intervention and control) on the dependent variable (attitude toward substance abuse). The basic hypotheses of this approach include variance equality and non-significant Levene's' test $(\mathrm{p}=<0.05)$, normality of the dependent variable and the linear relationship between the dependent and mediator variable which were obtained testing the research hypotheses. Data were analyzed using SPSS software version 18. Compact guide of the positive oriented and well-being treatment sessions is briefly presented based on the sessions order (table 1).

Both the first and second sessions included the clinical interview, referrals, mutual duties description and familiarity with the process and therapy and the final session was devoted to separation from the group and the results of evaluations. In the third session storytelling abilities and emotional (Pennebaker, 2012; King, Miner, 2000) were discussed. Therefore, it is better that the researcher knows about the ability of the twenty-four questionnaires VIA (Peterson, Seligman, 2004), thirty-five talent-finding capabilities of Clifton 2 (Rath, 2007) and also be familiar with cultural capabilities. Growing ability to express emotions and treatment were discussed in the fourth and fifth meetings. The sixth meeting devoted to the writing task based on forgiveness, but forgiveness did not mean forgetting, apologize or ask forgiveness of the offenders and the purpose was not reconciliation and peace (Enright, Coyle, 1998; McCullough, Witvliet, 2002; Seligman, 2002). But forgiveness is an action taken for him and to reduce psychological stress out and in case of not forgiving; his health might be at risk while the guilty person is not suffering from any disease (van Oyen Witvliet, Ludwig, Vander Laan, 2001). The idea to see and appreciate a person in general, can reduce the intensity of the hatred and accelerates the process of forgiveness (Reivich, 2004). Generous people have better mental health (Krause, Ellison, 2003).Understanding the thanksgiving structure at the seventh session is the confessional to the fact that there is something good and pleasurable in this world (Emmons, 2007). Thanksgiving is associated with positive psychological, physical and interpersonal outcomes (Emmons, McCullough, 2003) and requires attention to people and things that are often ignored or neglected (Snyder, Lopez, 2007). People who are thankful have higher levels of happiness and lower depression (Seligman et al, 2005).

Today, it is undisputed that thanksgiving is an incentive for friendship or prosocial behavior (socially desirable behavior) (Bartlett, DeSteno, 2006). Ninth session is based on the training content to the maximum (Schwartz, Ward, Monterosso, Lyubomirsky, White, 2002). At this stage, the trainee is encouraged for sufficient satisfaction rather than the maximum. Activeconstructive responding (Gable, Reis, Impett, Asher, 2004) in session ten had many advantages for the patient and those interacting with him. The studies confirmed that those who interact with 
others in active-constructive way, report more happiness and daily joy and satisfaction and have more confidence and show little difference in their relationships (ibid). The fun activity (Rashid, 2008) on twelfth session means an activity that involves the patients completely, so that they can use their individual capacity (Seligman, 2004). Moreover, the use of Enjoy techniques (tasting pleasure) increases positive experiences (Seligman, 2002; Bryant, Veroff, 2002). The pre-final session is devoted to the full meaning of life and the final session is for the separation from the treatment groups and providing feedback from clinical evaluation and interventions. The content of each session included a review of the previous session assignments, discussions, exercises and presentations of assignments for the next session.

\section{RESULTS}

The data were analyzed in both descriptive (mean, standard deviation) and inferential statistics (ANOVA test and Scheffe post hoc test) using SPSS software version 18, which are shown in the following tables. In Table 3, the demographic of the sample is provided in terms of educational levels and marital status.

Table 4 shows the descriptive data consisted of the average, minimum and maximum scores in the three groups. The lowest and highest average in the pre-test was devoted to the positiveoriented group and in post-test was devoted to the well-being treatment and control group. In Table 5, the results of ANOVA of attitude to drugs are presented.

Considering the results of Table 5, there was a significant difference in the variance of scores in the three groups ( $\mathrm{df}=2 / 33, \mathrm{~F}=16 / 03, \mathrm{P}>0.0001)$.

Scheffe's test was used to compare the mean scores of attitude to drug in three groups and the results are presented in Table 6.

According to the results, there is no significant difference between positive-oriented treatment and well-being groups at 99\% confidence level $(\mathrm{P}=0.208)$, but the positive-oriented treatment group and the control group $(\mathrm{P}<0.0001)$ and the well-being treatment and the control group $(\mathrm{P}=0.002)$ had significant differences in their attitude to drug.

\section{CONCLUSION}

Today, the positive -oriented treatment tries to create reconciliation between logic and emotion and acts as a complement to traditional treatments in clinical psychology, which is mainly damage-oriented approach. The future task of positive-oriented psychology is to understand the factors that make capabilities. The positive-oriented psychology requires the development of effective interventions for enhancing these potentials. This study was also conducted regarding the change from the problem focused approach to capability development approach. Positive- 


\section{The Effectiveness of Group Positive-Therapy (PPT) and Well-Being Therapy (WBT) on Attitude Towards Drug Abuse in Patients Under Methadone Maintenance Therapy}

oriented psychology and well-being treatment are emerging approach extracted from within the CBT, developed and validated by several clinical trials. They are considered as the most widely used cognitive-behavioral therapy approaches to treat addiction (Curry et al, 2001) and help these patients to deal effectively with problematic behavior by training techniques (Mollazadeh, Ashuri, 2009). The purpose of this study was to compare the effectiveness of positive-oriented treatment (PPT) Well-being therapy (WBT) as a group on the changing attitudes of patients treated with methadone to drug abuse. The results showed that the positive- oriented and wellbeing treatment had no significant difference in reducing drug attitudes, but both treatments had significant effect compared to the control group. Changing attitudes to drug was the factor that led addicts to the use of drug or vice versa discouraged them from using drugs (Ellis, 2002). It seems that both treatments have been able to create positive emotions to change their attitude towards drug use. The objective of this study was to create a negative attitude towards addiction. However, after reviewing the research literature, the researcher could not find a similar study but other researchers also confirmed the impact of cognitive behavioral therapy in patients with drug dependence (Fierro, 2009; Kathleen, 2002; Ashouri, Mollazadeh, Mohammadi, 2008; Nick, 2006; Ahghar, 2010; Momeni, Moshtagh-e-Beydokhti, Pourshahbaz, 2010; Dabaghi, Asgharnezhad, Atef Vahid, Bolhari, 2008; Jafari, Shahidi, Abedin, 2009). Cognitive-behavioral approach is a strategy which leads to change in thinking, reducing irrational beliefs and negative attitudes toward drug. The cognitive and behavioral interventions can be effective against drug-using false beliefs (Abolghasemi, Ahmadi, Kiamarsi, 2007; Alizadehsahraei, Khosravi, Besharat, 2010). The effectiveness positive-oriented psychotherapy was approved in the treatment of depression and creating happiness symptoms either in a group or individually (Seligman, Rashid, Parks, 2006). And the summarized and group from of the study in school children lead to increase in their wellbeing (Rashid, Anjum, 2008). The research results indicated the effectiveness and efficiency of therapy in the treatment of emotional disorders and emotional well-being (Fava et al, 1998; Fava, Tomba, 2009; Moeenizadeh, Kumar, 2010), stress reduction (Golbaryazdy, Sharbaf, Moyinizadeh, 2012) and the treatment of panic (Fava et al, 1998), respectively. The purpose of this study was to compare the effectiveness of positive-oriented treatment (PPT) Well-being therapy (WBT) as a group on the changing attitudes of patients treated with methadone to drug abuse. The results showed that the positive- oriented and well-being treatment had no significant difference in reducing drug attitudes, but both treatments had significant effect compared to the control group. A limitation of this study was the difficulty in making time coordination to participate in therapy sessions. In the end, it is recommended that positive -oriented and wellbeing treatment are examined for change in women's attitude toward drug use.

\section{LIMITATIONS}

This study has particular limitations. The first limitation of this study is a small sample size. Although the number of participants did not decrease in this study but small sample size is one of its limitation s that obstacles accurate measurement of program effect. The second limitation is related to using self-report tools. These tools have some essential problems 
(measurement error, lack of self in sight and etc.) The third limitation is related to lack of contextual and in dividual factors control. It is possible that participants overestimated effect of the program because of some contextual factors. Another possible hypothesis is that individuals overestimated the effect of the program because of person al willingness, optimism and factors like that. It is recommended, to conduct pseudo therapy programs (placebo program) on control group in future studies to control expected effect. It is also recommended to use samples with larger size to achieve a true effect size.

\section{Conflict of Interests}

The Authors have no conflict of interest.

\section{ACKNOWLEDGEMENT}

All Lavasan Clinicals staffs in Tehran and patients who have participated in this study are appreciated.

\section{REFERENCES}

Abolghasemi A, Ahmadi M, Kiamarsi A. (2007). The Relationship of Metacognition and Perfectionism with Psychological Consequences in the Addicts, Journal of Behavior Research. 5(2):73-79.[Persian]

Ahghar, G. (2010). Paper: Effectiveness of group counselling with cognitive-behaviioral approach on mental health of femail students. 4(14):7-14.

Alizadehsahraei OH, Khosravi Z, Besharat MA. (2010). Relationship of Irrational Beliefs wIth the Positive and Negative Perfectionism students in Noshahr city,Journal of Psychological Studies. 6(1):41-9.[Persian]

Ashouri, A., Mollazadeh, J., \& Mohammadi, N. (2008). The effectiveness of cognitivebehavioral group therapy on the improvement of coping skills and relapse prevention in addicted individuals. Iranian Journal of Psychiatry and Clinical Psychology, 14(3), 281-288. [Persian]

Bartlett, M. Y., \& DeSteno, D. (2006). Gratitude and prosocial behavior helping when it costs you. Psychological science, 17(4), 319-325.

Bryant, F. B., \& Veroff, J. (2002). Savouring: A process model for positive psychology. Unpublished manuscript.

Carroll, K. M. (2004). Behavioral therapies for co-occurring substance use and mood disorders. Biological psychiatry, 56(10), 778-784.

Curry, J. F., Wells, K. C., Lochman, J. E., Craighead, W. E., \& Nagy, P. D. (2001). Group and family cognitive behavior therapy for adolescent depression and substance abuse: A case study. Cognitive and Behavioral Practice, 8(4), 367-376.

Dabaghi P, Asgharnezhad F, Atef Vahid MK, Bolhari J. (2008). Effectiveness of group Cognitive therapy based on thinking of Supervisions (a wareness of mind) and spiritual 
schema activation and prevention of relapse in opioid use, Journal of Psychiatry and Clinical Psychology. 13(4): 366 -375.[Persian]

Daley DC , Marlatt GA. (2005). Relapse prevention. In: Lowinson JH, Ruiz P, Millman RB, Langrod JG, eds. Substance Abuse: A Comprehensive Textbook. 4th ed. Philadelphia, PA: Lippincott Williams \& Wilkins, 772-785.

Duckworth, A., Steen, T. A., \& Seligman, M. E. (2005). Positive psychology in clinical practice. Annu. Rev. Clin. Psychol., 1, 629-651.

Ellis A. (2002). Overcoming resistance's rational emotive behavior therapy integrated approach, New York: Springer.

Emmons, R. A. (2007). Thanks!: How the new science of gratitude can make you happier. Houghton Mifflin Harcourt.

Emmons, R. A., \& McCullough, M. E. (2003). Counting blessings versus burdens: an experimental investigation of gratitude and subjective well-being in daily life. Journal of personality and social psychology, 84(2), 377.

Enright, R. D., \& Coyle, C. T. (1998). Researching the process model of forgiveness within psychological interventions. Dimensions of forgiveness: Psychological research and theological perspectives, 139-161.

Fadayi Sade, F. (2009). Therapist's guide to positive psychological interventions, Tehran: roshd.

Fava, G. A., Rafanelli, C., Cazzaro, M., Conti, S., \& Grandi, S. (1998). Well-being therapy. A novel psychotherapeutic approach for residual symptoms of affective disorders. Psychological medicine, 28(02), 475-480.

Fava, G. A., \& Tomba, E. (2009). Increasing Psychological Well-Being and Resilience by Psychotherapeutic Methods. Journal of Personality, 77(6), 1903-1934.

Fierro, M, (2009). Recovering From Substace Abuse: Support Groups For GAY AND lesbian Adults: A Grant poroposal Unpublished Thesis for Master of Science California State University.

First, M. B., Spitzer, R. L., Gibbon, M., \& Williams, J. B. W. New York: Biometrics Research, New York State Psychiatric Institute; 2002. Structured Clinical Interview for DSM-IVTR Axis I Disorders, Research Version, Patient Edition.(SCID-I/P).

Gable, S. L., Reis, H. T., Impett, E. A., \& Asher, E. R. (2004). What do you do when things go right? The intrapersonal and interpersonal benefits of sharing positive events. Journal of personality and social psychology, 87(2), 228.

Golbaryazdy, H, Sharbaf, H, Moyinizadeh, M. (2012). efficacy Welfare stress and psychological well-being infertile women. Gynecology and Infertility Iran Iranian Journal of Obstetrics, Gynecology and Infertility, 15(2),49-56. [Persian]

Hyman, S.E., \& Malenka, R.C. (2001). Addiction and the brain: the neurobiology of compulsion and its persistence. Nature Review Neuroscience, 2 (10), 695-703. 
Jafari M, Shahidi Sh, Abedin A. (2009). Comparing the effectiveness of Cognitive Behavioral Therapy and Trans- theoretical Model on improving abstinence self-efficacy in substance dependent adolescents, Journal of Behavior Research. 7(1):1-12 [Persian]

Linley, P. A., \& Joseph, S. (Eds.). (2004). Positive psychology in practice (pp. 713-731). Hoboken, NJ: Wiley.

Lopez, S. J., Snyder, C. R., \& Rasmussen, H. N. (2003). Striking a vital balance: Developing a complementary focus on human weakness and strength through positive psychological assessment.

Kathleen Carroll. (2002). Therapy manuals for drug addiction, a cognitive behavioral approach treating cocaine addiction. Translate by Bakhshipur Rudsari A, Mohamadkhani SH. Espand honar.

King, L. A., \& Miner, K. N. (2000). Writing about the perceived benefits of traumatic events: Implications for physical health. Personality and social psychology bulletin, 26(2), 220-230.

Krause, N., \& Ellison, C. G. (2003). Forgiveness by God, forgiveness of others, and psychological well-being in late life. Journal for the scientific study of religion, 42(1), 77-93.

McCullough, M. E., \& Witvliet, C. V. (2002). The psychology of forgiveness. Handbook of positive psychology, 2, 446-455.

Mathers, C. D., Bernard, C., Iburg, K. M., Inoue, M., Ma Fat, D., Shibuya, K., ... \& Xu, H. (2003). Global burden of disease in 2002: data sources, methods and results. Geneva: World Health Organization.

Mollazadeh J, Ashuri A.(2009). Effectiveness of group cognitive behavioral therapy in Preventing recurrence and improving the mental health of addicts, Daneshvar Shahed University (Raftar) 2009;34:1-12 [persion]

Moeenizadeh, M., \& Kumar, S. K. K. (2010). Well-being therapy (WBT) for depression. International Journal of Psychological Studies, 2(1), p107.

Momeni F, Moshtagh-e- Beydokhti N, Pourshahbaz A. (2010). The effectiveness of cognitive behavioral group therapy for reducing hunger and improving depression and anxiety symptoms in opiate addicts undergoing methadone maintenance therapy, Journal of Etiyad pazhohi. 3 (11): 83-97[Persian]

Naghavi, M. (2006).Transition in Health Status in the Islamic Republic of Iran. Iranian Journal of Epidemiology, 2(1), 45-57.

Nick M. (2006). Cognitive-Behavioral Therapy and irrational beliefs: A Case Series pilot study, Behavioral and cognitive psychotherapy. 34:107-111.

Pennebaker, J. W. (2012). Opening up: The healing power of expressing emotions. Guilford Press.

Peterson, C., \& Seligman, M. E. (2004). Character strengths and virtues: A handbook and classification. Oxford University Press.

Peterson, C., \& Seligman, M. E. (2004). Character strengths and virtues: A handbook and classification. New york: Oxford University Press. 
Rashid t, positive psychotherapy. in: lopez sj, e d. positive psychology:exploring the best in people: vol.4. westport, ct: praeger publisher; 2008:187-217.

Rath, T. (2007). Strengths Finder 2.0. Gallup Press.

Rashid, T., \& Anjum, A. (2008). Positive psychotherapy for young adults and children. Handbook of depression in children and adolescents, 250-287.

Rafanelli, C., Park, S. K., \& Fava, G. A. (1999). New psychotherapeutic approaches to residual symptoms and relapse prevention in unipolar depression. Clinical Psychology \& Psychotherapy, 6(3), 194-201.

Rashid, T., \& Seligman, M. E. (2008). Positive psychotherapy. Positive psychology: Exploring the best in people, 4, 187-217.

Reivich, K. (2004). Letting go of grudges. Assignment instructions for MEP Seligman's Authentic Happiness Coaching Program.

Rezai, A, m., Delaware, A., Najafi, M. (2012). Construction and validation of a questionnaire measuring attitudes toward drugs in junior high school students in the country. Journal of Etiyad pazhohi. 6 (24): 37-54 [Persian]

Roozen, H. G., de Waart, R., van der Windt, D. A., van den Brink, W., de Jong, C. A., \& Kerkhof, A. J. (2006). A systematic review of the effectiveness of naltrexone in the maintenance treatment of opioid and alcohol dependence. European neuropsychopharmacology, 16(5), 311-323.

Ruini, C. Fava, GA. (2004). Clinical applications of well-being therapy. Positive psychology in practice,371-387.

Ryff, C. D. (1989). Happiness is everything, or is it? Explorations on the meaning of psychological well-being. Journal of personality and social psychology, 57(6), 1069.

Schwartz, B., Ward, A., Monterosso, J., Lyubomirsky, S., White, K., \& Lehman, D. R. (2002). Maximizing versus satisficing: happiness is a matter of choice. Journal of personality and social psychology, 83(5), 1178.

Seligman, M. E. (2004). Authentic happiness: Using the new positive psychology to realize your potential for lasting fulfillment. Simon and Schuster.

Seligman, M. E. (2002). Positive psychology, positive prevention, and positive therapy. Handbook of positive psychology, 2, 3-12.

Seligman, M. E., Rashid, T., \& Parks, A. C. (2006). Positive psychotherapy. American psychologist, 61(8), 774.

Seligman, M. E., Steen, T. A., Park, N., \& Peterson, C. (2005). Positive psychology progress: empirical validation of interventions. American psychologist, 60(5), 410.

Sharifi, V., Assadi, S. M., Mohammadi, M. R., Amini, H., Kaviani, H., Semnani, Y., ... \& Jalali, M. (2009). A persian translation of the structured clinical interview for diagnostic and statistical manual of mental disorders: psychometric properties. Comprehensive psychiatry, 50(1), 86-91.

Snyder, C. R., \& Lopez, S. J. (2007). Positive psychology. The Scientific and Practical. 
Termorshuizen, F., Krol, A., Prins, M., Geskus, R., van den Brink, W., \& van Ameijden, E. J. (2005). Prediction of relapse to frequent heroin use and the role of methadone prescription: an analysis of the Amsterdam Cohort Study among drug users. Drug and alcohol dependence, 79(2), 231-240.

van Oyen Witvliet, C., Ludwig, T. E., \& Vander Laan, K. L. (2001). Granting forgiveness or harboring grudges: Implications for emotion, physiology, and health. Psychological Science, 12(2), 117-123.

\section{TABLES}

Table 1: summarized content of the positive-oriented psychotherapy sessions

\begin{tabular}{|c|c|}
\hline Session & Subject \\
\hline First & Clinical interview \\
\hline Second & $\begin{array}{l}\text { Introducing positive-oriented therapy and obligations of the parties in therapy } \\
\text { sessions and encourage the client to story -writing, offer forms, pre-test }\end{array}$ \\
\hline Third & Speaking of capabilities from the narrative and introduce positive references \\
\hline Fourth & $\begin{array}{l}\text { Raising the educational superior strength and positive emotions and plans to } \\
\text { implement these capabilities, understanding of positive emotions and home } \\
\text { office homework Thanksgiving }\end{array}$ \\
\hline Fifth & $\begin{array}{l}\text { Checking the previous session assignments, practice tools, negative emotions } \\
\text { such as anger and protest and examine their impact on the creation and } \\
\text { persistence of cases of depression and helplessness }\end{array}$ \\
\hline Sixth & $\begin{array}{l}\text { Checking the previous session assignments, familiar with the structure of } \\
\text { forgiveness as a tool that can transform negative emotions into positive, domestic } \\
\text { task of writing a forgiveness }\end{array}$ \\
\hline Seventh & $\begin{array}{l}\text { Checking the previous session assignments, Introduction to thanksgiving } \\
\text { construct, thanksgiving positive effect on good and bad memories, domestic } \\
\text { task of writing a thanks letter }\end{array}$ \\
\hline Eighth & $\begin{array}{l}\text { Review and assessment of progress between health authorities in writing a } \\
\text { thanksgiving and forgiveness letter and discussing the client feedback on } \\
\text { treatment process }\end{array}$ \\
\hline Ninth & $\begin{array}{l}\text { Encouraging client to have satisfaction and contentment to the maximum, to } \\
\text { create harmony between expectations and reality, the task of devising a } \\
\text { satisfactory plan at home }\end{array}$ \\
\hline Tenth & $\begin{array}{l}\text { Checking the previous session assignments, exercises active and constructive } \\
\text { response and the projecting a family meeting }\end{array}$ \\
\hline Eleventh & $\begin{array}{l}\text { Recognize and acknowledge the highest capacity of the family members for } \\
\text { meaning in life }\end{array}$ \\
\hline Twelfth & Understanding the concept of pleasure and planned fun activities \\
\hline Thirteenth & Find meaning through the use of the capabilities of the secretary (third session \\
\hline Fourteenth & $\begin{array}{l}\text { treatment) in order to ultimately helping others and discuss a complete life } \\
\text { separating from the Group / Periodic meetings determination tests and the results } \\
\text { of the analysis of data }\end{array}$ \\
\hline
\end{tabular}


The Effectiveness of Group Positive-Therapy (PPT) and Well-Being Therapy (WBT) on Attitude Towards Drug Abuse in Patients Under Methadone Maintenance Therapy

Table 2: summarized content of the well-being psychotherapy sessions

\section{Session Subject}

First Interview

Second The definition of the curriculum - and targets for drug therapy in the treatment of participants / offer forms and diary / mutual obligations stipulated in the program / pre-test

Third In the framework of well-being therapy / therapist role and responsibilities of the authorities discussed / role of positive emotions in the continued absence of drug dependence arises / worksheet introduce your registration

Fourth Check the previous session assignments / Well-being identification courses to help discover the positive emotions / motivate a person to record events in the diary / worksheet rid of hatred

Fifth Check the previous session assignments / optimism and hope / clients are guided to think about when you fail in a major / The clients are asked to pay attention to when one closes / opens the doors to another / work leaves open new doors in life.

Sixth Check the previous session assignments / her acceptance of the role of the mind / reception experience rather than denying or trying to forget their failed / worksheet a hope

Seventh Check the previous session assignments / use of public places in the discovery of irrational reasoning / purpose of the benefit and the long-term goals in life / worksheet blessings

Eighth Worksheet blessings / empathy as a driver of positive emotions / control environment as a component of mental health / worksheet a forgiveness

Ninth Check the previous session assignments / study of social cognitive development and possible periods of recession / slowdown in the creation of inefficient knowledge / worksheet of emotions

Tenth Check the previous session assignments / recognition is discussed as durable thanks again and good and bad memories are highlighted with emphasis on appreciation / practical examples of the impact of optimism and pessimism on consumption and avoiding consumption

Eleventh Check homework before the meeting / discussion of positive relationships with others, to promote it and understand its role in mental health

Twelfth Understanding the components of personal growth, embracing new experiences and a sense of evolution.

Thirteenth Check the previous session assignments / presentation component of autonomy and discussion of positive relationships with others/ review

Fourteenth progress/ post-test

Separating from the Group / Periodic meetings with determination tests and the results of the analysis of data 
The Effectiveness of Group Positive-Therapy (PPT) and Well-Being Therapy (WBT) on Attitude Towards Drug Abuse in Patients Under Methadone Maintenance Therapy

Table 3: educational levels and marital status in three groups of well-being treatment, positive-oriented treatment and control group

\begin{tabular}{|c|c|c|c|c|c|}
\hline Frequency & $\begin{array}{l}\text { High } \\
\text { degree } \\
\text { lower }\end{array}$ & $\begin{array}{r}\text { school } \\
\text { and }\end{array}$ & $\begin{array}{l}\text { Bachelor and } \\
\text { higher }\end{array}$ & Single & Married \\
\hline number & 17 & & 15 & 11 & 21 \\
\hline percent & $53 / 1$ & & $46 / 9$ & $34 / 4$ & $65 / 6$ \\
\hline
\end{tabular}

Table 4: attitude to drugs in three groups of well-being treatment, positive-oriented treatment and control group

\begin{tabular}{rrrrrrr}
\multicolumn{1}{c}{ group } & \multicolumn{2}{l}{ mean } & \multicolumn{2}{l}{$\begin{array}{l}\text { highest } \\
\text { score }\end{array}$} & \multicolumn{3}{l}{$\begin{array}{l}\text { Lowest } \\
\text { score }\end{array}$} \\
\cline { 2 - 7 } N=12 & Pre-test & Post-test & Pre-test & Post-test & Pre-test & Post-test \\
\hline $\begin{array}{r}\text { well-being } \\
\text { positive- }\end{array}$ & $101 / 20$ & $121 / 10$ & 123 & 136 & 80 & 101 \\
$\begin{array}{r}\text { oriented } \\
\text { control }\end{array}$ & $99 / 20$ & $112 / 5$ & 126 & 135 & 82 & 95 \\
\hline
\end{tabular}

Table 5: ANOVA of attitude to drugs in three groups

\begin{tabular}{lrrrrr}
\hline \begin{tabular}{l} 
Source of \\
\multicolumn{1}{c}{ change }
\end{tabular} & $\begin{array}{r}\text { Sum } \\
\text { Squares }\end{array}$ & df & $\begin{array}{r}\text { Mean } \\
\text { Squares }\end{array}$ & F value & Sig. \\
\hline $\begin{array}{l}\text { Intergroup } \\
\text { Within the }\end{array}$ & $2850 / 44$ & 2 & $1425 / 22$ & & \\
group & $2934 / 03$ & 33 & $88 / 91$ & $16 / 03$ & $\mathrm{p}<0 / 00001$ \\
Total & $5784 / 47$ & 35 & & & \\
\hline
\end{tabular}

Table 6: Scheffe's mean scores of attitude to drug in three groups

\begin{tabular}{rrrr}
\hline Treatment & well-being & positive-oriented & control \\
\cline { 2 - 4 } & $\mathrm{M}=13 / 24$ & $\mathrm{M}=19 / 91$ & $\mathrm{M}=1 / 41$ \\
\hline well-being & - & $0 / 208$ & $0 / 002$ \\
positive-oriented & $0 / 208$ & - & $0 / 00001$ \\
control & $0 / 002$ & $0 / 00001$ & - \\
\hline
\end{tabular}

